\title{
PROTOTIPE PENGONTROLAN RUNNING TEXT MENGGUNAKAN VOICE DAN ARDUINO UNO VIA SMARTPHONE ANDROID
}

\author{
Ferry Sudarto ${ }^{1}$ \\ Moch.Ibnu safari ${ }^{2}$ \\ Muhammad Fazri ${ }^{3}$ \\ Dosen Jurusan Sistem Komputer STMIK Raharja ${ }^{1}$, Dosen Jurusan Sistem Komputer STMIK Raharja ${ }^{2}$, \\ Alumni STMIK Raharja Jurusan Sistem Komputer ${ }^{3}$ \\ Email:ferry.sudarto@raharja.info, ibnu.safari@raharja.info,fazri@ raharja.info
}

Diterima: 5 Desember 2016/ Disetujui : 19 Desember 2016

\begin{abstract}
Running text or commonly known as text running a medium to deliver information that is most often encountered as a means of advertising that are informative. Running text display is generally in the form of LED-LED are connected and assembled into a row of LED or may be a dot matrix. Submission of information by displaying the running text has not been effective and efficient in terms of use. There are still shortcomings that enable people to experience vision errors and too long waiting for the text to be displayed. Thus the necessary tools to deliver information that can work optimally to minimize shortages by designing a control tool running text using voice (voice) and arduino uno. This tool uses a series of android smartphones facilities to provide input sound is converted into a data string and compiled in arduino using serial communications, and will be displayed on the LED Dotmatrix as output. Submission of information by using running text that comes with using sound can improve efficiency and effectiveness in the use and also the time required so that it can reduce the level of difficulty of the user in receiving the information.
\end{abstract}

Keywords : Running Text, DotMatrix, Arduino Uno

\begin{abstract}
ABSTRAK
Running text atau yang biasa dikenal dengan text berjalan merupakan media penyampaian informasi yang paling sering dijumpai sebagai sarana advertising yang bersifat informatif. Display Running text pada umumnya berupa led-led yang disambung dan dirangkai menjadi deretan led ataupun dapat berupa dot matrix. Penyampaian informasi dengan menampilkan running text tersebut belum efektif dan efisien dalam hal penggunaan. Masih terdapat kekurangan yang memungkinkan manusia mengalami kesalahan penglihatan dan terlalu lama menunggu text yang akan ditampilkan. Maka dari itu dibutuhkan alat penyampaian informasi yang dapat bekerja secara maksimal untuk meminimalisir kekurangan dengan merancang alat pengontrolan running text menggunakan suara (voice) dan arduino uno. Rangkaian alat ini menggunakan fasilitas smartphone android untuk memberikan inputan suara yang dirubah menjadi data string lalu di compile di arduino menggunakan komunikasi serial, dan akan ditampilkan pada LED DotMatrix sebagai output. Penyampaian informasi dengan menggunakan running text yang dilengkapi dengan menggunakan suara dapat meningkatkan efisiensi dan efektifitas dalam hal penggunaan dan juga waktu yang dibutuhkan sehingga hal ini dapat mengurangi tingkat kesulitan user dalam menerima informasi.
\end{abstract}

Kata Kunci : Running Text, DotMatrix, Arduino Uno

\section{PENDAHULUAN}

Saat ini penyampaian informasi semakin cepat sehingga media informasi yang berkembang semakin inovatif dan menarik. Dalam menyampaikan suatu informasi kita harus kreatif agar para user yang menerima informasi tersebut dapat terkesan.

Salah satu media penyampaian informasi adalah running text, running text atau tulisan berjalan adalah suatu media elektronik yang bersifat informatif. Running Text banyak dipilih orang 
sebagai sarana advertising, selain tampilannya yang sangat menarik, running text sendiri memiliki daya tarik bagi orang - orang yang melihatnya.

Penyampaian informasi dengan menampilkan running text tersebut belum efektif dan efisien dalam hal penggunaan. Masih terdapat kekurangan yang memungkinkan manusia mengalami kesalahan penglihatan dan terlalu lama menunggu text yang akan ditampilkan.

Running text yang ada yaitu berupa led-led yang disambung dan dirangkai menjadi deretan led ataupun dapat berupa dot matrix. Dot matrix merupakan deretan led yang membentuk array dengan jumlah kolom dan baris tertentu, sehingga titik-titik yang menyala dapat membentuk suatu karakter angka, huruf, tanda baca dan sebagainya.

Dalam penelitian ini, peneliti menggunakan menggunakan voice dan arduino uno untuk pengontrolan Running Text, alat ini dirancang menyerupai miniatur gapura yang dilengkapi dengan komponen seperti: Objek, smartphone untuk penerima perintah suara, Arduino Uno, Bluetooth, modul Bluetooth $\mathrm{HC} 05$ dan dot matrik yang dijadikan sebagai output running text untuk mendukung kinerja alat tersebut.

Alat ini dapat bekerja dengan efektif dan efisien, dengan menggunakan perintah suara yang diinputkan melalui smartphone display running text dapat tampil dengan mudah dan cepat. Informasi yang didapat lebih akurat dan presisi jika dibanding dengan display running text tanpa menggunakan suara.

\section{PERMASALAHAN}

Media penyampaian informasi Running Text merupakan suatu inovasi yang menarik dalam perkembangan teknologi informasi saat ini. Informasi yang disampaikan pada umumnya diterima melalui berita dengan tulisan yang ditulis pada media cetak, internet dan lain-lain. Hal ini dapat menyebabkan informasi yang diterima oleh pengguna tidak akurat karena adanya keraguan saat informasi diterima. Sebagai salah satu contoh yaitu pada saat seseorang menuliskan berita atau informasi penting yang akan disampaikan, orang tersebut salah mendengar atau mengetahui kebenaran isi berita tersebut. Penyampaian informasi ini dapat dirancang menjadi alat pengontrolan running text untuk meningkatkan inovasi yang ada dengan menggunakan suara dan arduino uno dengan memanfaatkan smartphone android sebagai sarana penunjang dalam penyampaian informasi.

Pengontrolan running text menggunakan voice ini menggunakan jaringan Bluetooth untuk mengkomunikasikan perangkat android ke arduino, user hanya perlu membuka Aplikasi running text di smartphone dan memberikan inputan suara lalu suara akan di rubah menjadi data String,lalu data String yang akan di input ke running text dari smartphone android akan di kirimkan ke arduino dan String akan di compile di arduino menggunakan komunikasi serial, dan akan di tampilkan pada LED DotMatrix.

Bagaimana menggunakan inputan suara menggunakan smartphone android yang harus berkomunikasi dengan arduino? Prototipe alat ini menggunakan Smartphone Android dan arduino uno, android digunakan untuk menerima inputan suara yang nantinya akan di proses oleh arduino, media komunikasi yang digunakan oleh arduino dan android adalah data serial yang menggunakan Bluetooth HC-05. Bagaimana penggunaan running text untuk menampilkan pesan pada LED DotMatrix? Pengontrolan running text pada prototype ini menggunakan sebuah aplikasi android yaitu Running Text Message untuk merekam sebuah inputan suara, yang akan diproses oleh arduino dengan output yang akan di tampilkan pada running text LED DotMatrix. Bagaimana penggunaan arduino uno untuk menampilkan running text? Menggunakan program Arduino untuk menuliskan listing program dan menyimpannya dengan file yang berekstensi .pde, dan bootloader Arduino Uno sebagai media yang digunakan untuk mengupload program ke dalam mikrokontroler, sehingga mikrokontroler dapat bekerja sesuai dengan yang diperintahkan dengan mengahasilkan running text yang akan ditampilkan.

\section{LITERATURE REVIEW}

Banyak penelitian sebelumnya dilakukan mengenai pengukuran berbasis mikrokontroler. Dalam upaya mengembangkan dan menyempurnakan alat ini perlu dilakukan studi pustaka (literature review) sebagai salah satu dari penerapan metode penelitian yang akan dilakukan. Manfaat dari studi pustaka (Literature Review) ini yaitu: 
1. Penelitian yang telah dilakukan oleh Sandi Purnama (2013) dari Institut Teknologi Telkom sebagai bentuk Tugas Akhir dengan judul "Perancangan dan Implementasi Sistem Penampilan Running Text dengan Data Berbasis Website". Pada Tugas Akhir ini dibuat sebuah perangkat running text dengan bantuan sistem minimum jenis arduino uno yang di dalamnya terdapat sebuah mikrokontroler ATMEGA 328. Informasi pada running text dapat diperbarui melalui sebuah website yang dibuat khusus untuk mengupdate informasi. Informasi pada website kemudian dikirim, lalu ethernet shield yang telah terpasang dengan arduino uno menerima data dan arduino uno mengolahnya untuk kemudian data tersebut ditampilkan pada panel LED matrix.

2. Penelitian yang telah dilakukan oleh Benny Julisha Pratida (2013) dari Universitas Tanjungpura Pontianak sebagai bentuk Jurnal dengan judul "Perancangan Display LED Dot Matrix Menggunakan Mikrokontroler Atmega32". Pada Jurnal ini penulis menggunakan mikrokontroler ATmega32 sebagai master controller dari sistem dan aplikasi Visual Basic sebagai aplikasi dari data karakter pengirim yang akan disajikan ke Tampilan LED Dot Matrix. Untuk memperbarui informasi yang akan disajikan, pengguna hanya mengetik data karakter yang akan dikirim ke aplikasi yang diterapkan oleh Visual Basic. Aplikasi ini disebut Input Data Matrix atau IDM. Data karakter yang bisa dikirim maksimum hanya 200 karakter termasuk ruang. Sementara waktu transfer data yang diperlukan untuk mengirimkan karakter data atau artikel tentang Tampilan LED Dot Matrix adalah 10,67 detik.

3. Penelitian yang telah dilakukan oleh Evy Cristanto Sri Nugroho (2013) dari Universitas Indonesia sebagai bentuk Tugas Akhir dengan judul "Papan Informasi Elektronik Dengan PS2 Keyboard". Pada Tugas Akhir ini penulis menggunakan Papan informasi elektronik ini terdiri dari ATMega8535 sebagai Pengolah dan penyimpan data,LCD untuk tampilan informasi tulisan bagi operator,power supply,dot matrix display serta melibatkan PS2 keyboard untuk memasukkan data. Dot matrix sebagai display dapat menampilkan tulisan bergeser dengan kriteria kecepatan looping 3.06s dan setiap karakter dapat dimunculkan dengan selang waktu sekitar 95ms.

4. Penelitian yang telah dilakukan oleh Sigit Maulana Kuncoro (2013) dari STMIK Raharja sebagai bentuk Tugas Akhir dengan judul "SMS Sebagai Perubah Informasi Matriks LED Berbasis AVR ATmega8 Pada Perguruan Tinggi Raharja". Pada Tugas Akhir ini penulis menggunakan Mikrokontroler ATmega8 dan LED.LED-LED yang disusun dalam kolom dan baris disebut dengan Matriks LED. Matriks LED ini yang kemudian digunakan untuk memberikan informasi yang menarik kepada seluruh mahasiswa dan biasanya ditampilkan dengan efek tulisan berjalan. Dalam prosesnya mikrokontroler akan menerima data informasi berupa string melalui SMS (Short Message Service), string ini yang akan dirubah menjadi display pada Matrix LED.

5. Penelitian yang telah dilakukan oleh Agung Alpurqon (2014) dari STMIK Raharja sebagai bentuk Tugas Akhir dengan judul "Sistem Pengendali Pintu Pagar Secara Otomatis Menggunakan Aplikasi Voice Command Pada Smartphone Android Os". Pada Tugas Akhir ini penulis bertujuan untuk membuat suatu alat yang dapat di kontrol melalui media suara yang nantinya dapat mengontrol pintu pagar. Dengan menggunakan mikrokontroler ATMega 8 sebagai otak untuk mengolah data yang masukkannya berupa inputan suara dari aplikasi voice command, kemudian data dikirim kerangkaian mikrokontroler ATMega 8 secara serial dengan menggunakan jaringan bluetooth. Pada sistem mekanik terdapat motor DC yang befungsi untuk menggerakan sebuah roda pintu, lock automatic system atau sistem kunci otomatis untuk mengunci pintu secara otomatis, sistem switch menggunakan magnetik switch untuk menentukan titik berhenti. Untuk sistem pengturan motor dc menggunakan rangkaian relay 12 vlt, dan untuk modul bluetooth yang digunakan adalah model bluetooth HC-05.

6. Penelitian yang telah dilakukan oleh Muhamad Bintar (2013) dari STMIK Raharja sebagai bentuk Tugas Akhir dengan judul "Sistem Pengontrolan Lampu Menggunakan Input Suara Berbasis Android". Pada Tugas Akhir ini penulis bertujuan untuk mengontrol lampu menyalakan atau mematikan lampu menggunakan inputan suara. 
Dalam penelitian ini menggunakan Mikrokontroler ATmega 8 sebagai otak untuk menerima data string voice yang dikirim dari Smartphone melalui jaringan Bluetooth

Dari enam Literature Review yang ada, telah banyak penelitian mengenai tentang Running Text,Android,Voice,Smartphone dan Pengontrolan. Di samping itu juga ada pembahasan mengenai perancangan beberapa alat Pengontrolan Running Text yaitu Perancangan Display LED Dot Matrix Menggunakan Mikrokontroler Atmega32, Papan Informasi Elektronik Dengan PS2 Keyboard.Maka dari itu penulis mengambil satu sample atau contoh untuk dijadikan acuan dari ke 6 (enam) literature review diatas yaitu dengan judul SMS Sebagai Perubah Informasi Matriks LED Berbasis AVR ATmega8 Pada Perguruan Tinggi Raharja yang menggunakan jenis penelitian dan pengembangan. Pada penelitian tersebut peneliti belum menggunakan atau memanfaatkan operating system android sebagai interface .

\section{PEMBAHASAN}

Pengontrolan running text menggunakan voice ini menggunakan jaringan Bluetooth untuk mengkomunikasikan perangkat android ke arduino, user hanya perlu membuka Aplikasi running text di smartphone dan memberikan inputan suara lalu suara akan di rubah menjadi data String,lalu data String yang akan di input ke running text dari smartphone android akan di kirimkan ke arduino dan String akan di compile di arduino menggunakan komunikasi serial, dan akan di tampilkan pada LED DotMatrix. Agar mudah dipahami maka penulis membuat diagram blok dan alur kerjanya

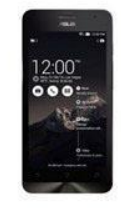

1

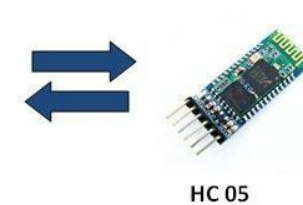

2

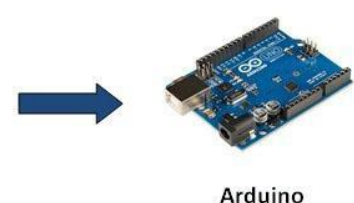

3

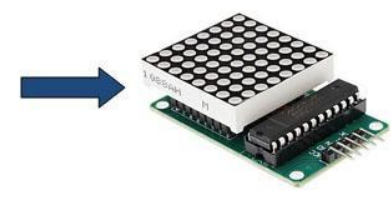

4

Gambar 1. Diagram Blok

Keterangan dan penjelasan Diagram Blok diatas adalah sebagai berikut :

1. Smartphone android merupakan perangkat yang digunakan untuk menjalankan aplikasi android yang berfungsi untuk input suara yang akan menampilkan karakter yang nantinya akan ditampilkan pada papan dotmatrix.

2. Bluetooth HC-05 merupakan gatwey antara smartphone dengan arduino menggunakan media komunikasi Bluetooth

3. Arduino merupakan interface yang digunakan untuk komunikasi antara smartphone dengan arduino melalui Bluetooth HC-05, arduino uno merupakan kontroler untuk memproses data yang dikirim oleh smart phone.

4. Dotmatrix merupakan alat output yang digunakan untuk menampilkan informasi berupa text pada LED. 


\section{FLOWCHART SISTEM}

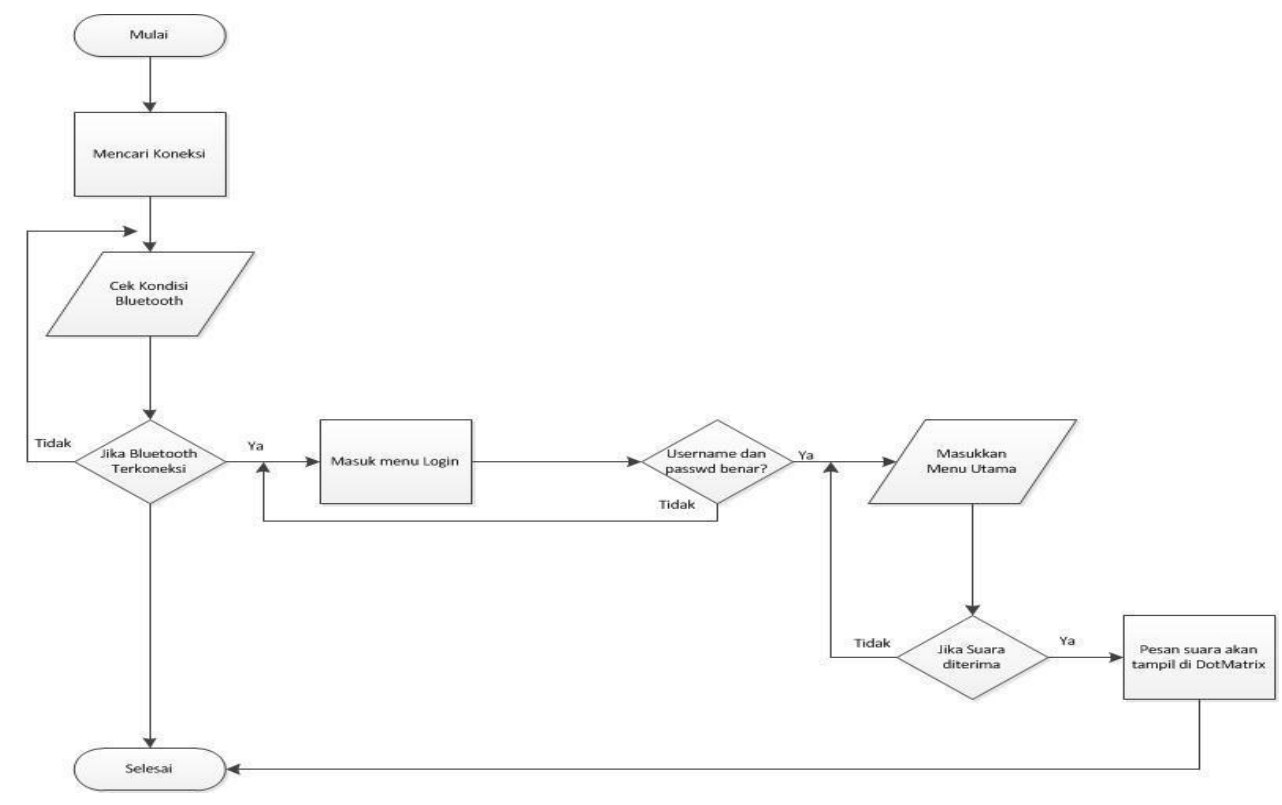

Gambar 2. Flowchart Sistem

Program diawali dengan mulai bekerja pada aliran proses flowchart sistem pengontrolan running text menggunakan voice kemudian mencari koneksi bluetooth yang tersedia. Jika bluetooth terkoneksi maka sistem akan menuju pada menu login dan jika tidak sistem akan kembali untuk mencari koneksi kembali. Pada saat login user harus memasukkan username dan password, jika benar sistem akan menuju ke halaman utama sistem dan jika password atau username salah maka sistem akan kembali menuju menu login. Setelah masuk ke halaman utama user menginpukan suara yang diperintahkan lalu jika pesan diterima maka pesan yang telah dinputkan akan tampil di dotmatrix dan jika tidak akan kembali ke halaman utama. Sistem Selesai.

\section{RANCANGAN PENGONTROLAN RUNNING TEXT}

Prototipe Pengontrolan Running Text Menggunakan Voice Dan Arduino Uno Via Smartphone Android ini disusun dengan menyerupai miniatur gapura. Alat ini dilengkapi dengan komponen seperti: Objek, smartphone untuk penerima perintah suara, Arduino Uno, Bluetooth, modul Bluetooth HC 05 dan dot matrik yang dijadikan sebagai output running text untuk mendukung kinerja alat tersebut. Bahan dalam perancangan prototipe terbuat dari kayu dan acrylic sebagai pembentuk miniatur gapura
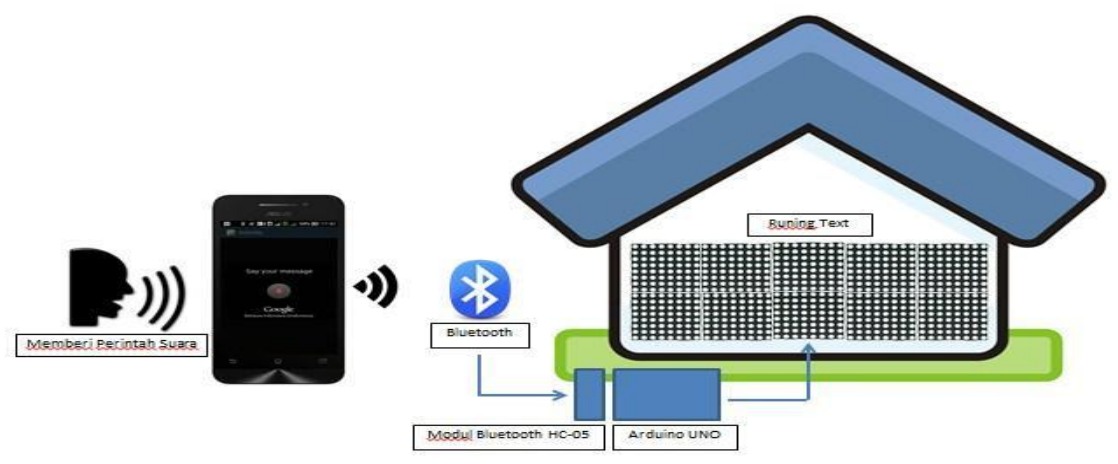

Gambar 3. Perancangan Prototipe 


\section{Analisa Program Pada Mikrokontroler}

Proses analisa dilakukan untuk mendapatkan kesesuaian antara perangkat keras yang sudah diuji coba dengan perangkat lunak yang telah deprogram ke dalam Arduino. Penulisan listing program menggunakan software Arduino Untuk lebih jelas mengenai pembahasan analisa program pada mikrokontoler yang akan dilakukan dapat dilihat di bawah ini .

1.

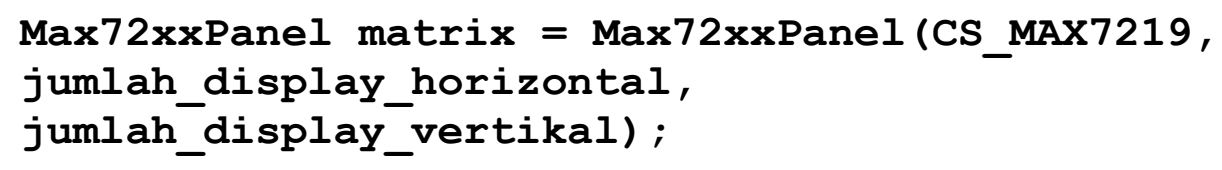

Koding ini berfungsi untuk mendeklarasikan seri dari iC dan jumlah dot-matrix yang terpasang secara horizontal dan vertical.

2.

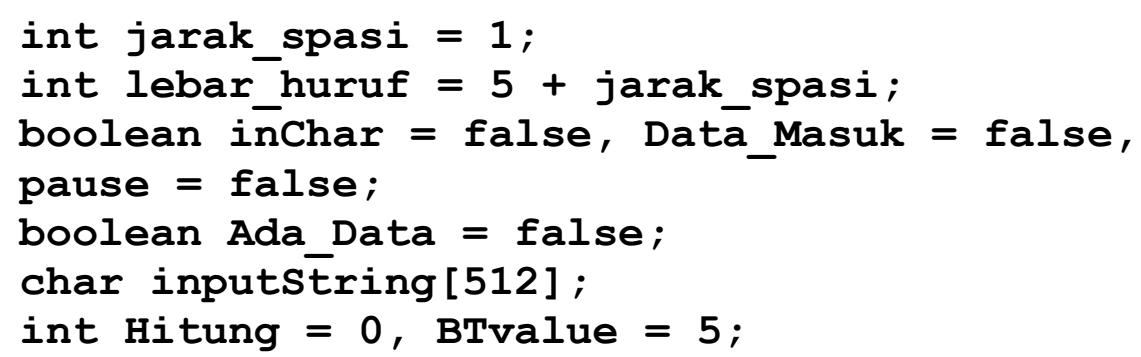

Koding ini di maksudkan untuk menentukan jarak spasi,lebar huruf dan batasan jumlah karakter yang akan di tampilkan pada Running Text.

3.

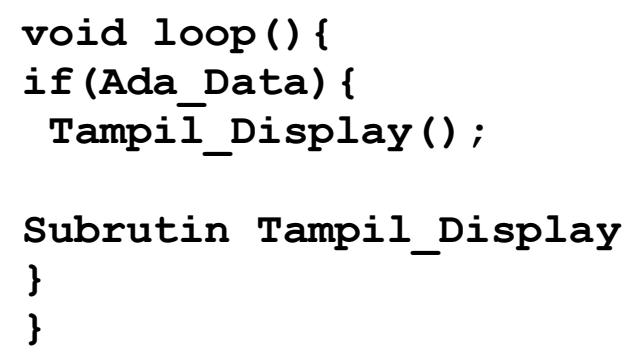

Koding ini di maksudkan untuk memanggil Subrutin Tampilan utama Display 
4.

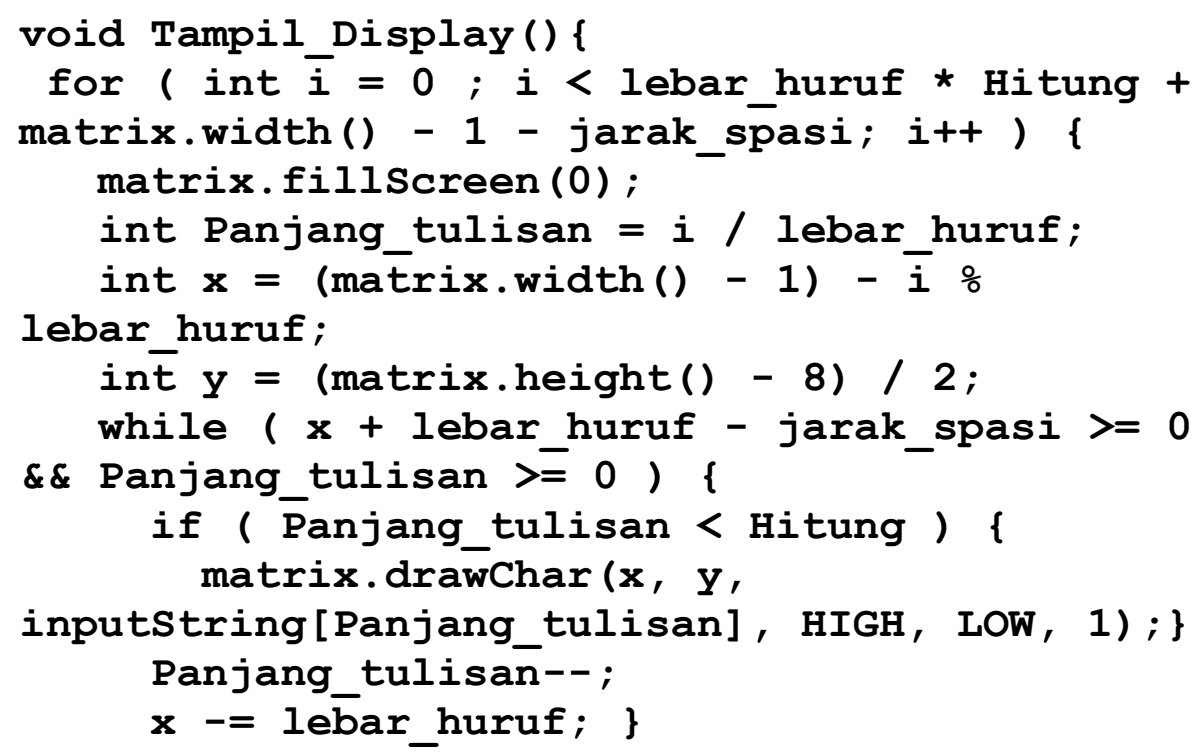

Koding ini di berfungsi untuk menampilakan karakter display pada running text.

\section{UJI COBA DAN IMPLEMENTASI}

\section{Uji Coba}

LED Dot matrix adalah sebuah komponen yang tersusun atas sejumlah LED yang berbentuk matriks. Dalam pengujian ini menggunakan Modul dot matrix $8 \mathrm{X} 8$, dalam pengujian ini menggunakan modul Dot Matrix sebanyak 8 buah Dot Matrix.

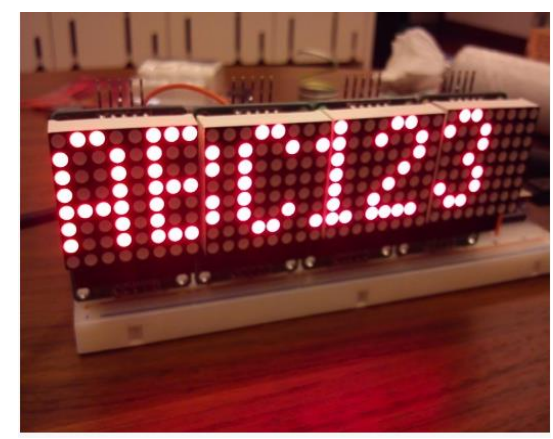

Gambar 4. Pengujian Dot Matrix berikut:

Adapun listing Program yang digunakan dalam uji coba dari rangkaian di atas adalah sebagai

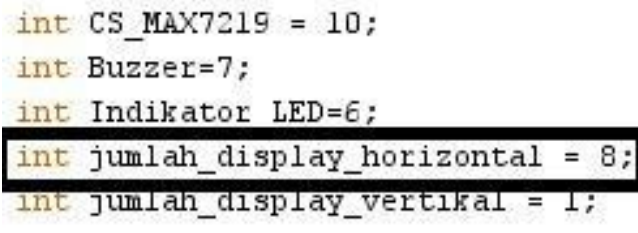

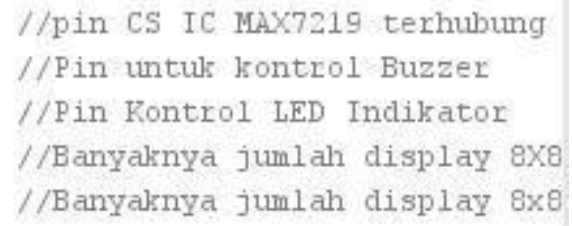

Gambar 5. Listing program pengujian Dotmatrix 


\section{Implementasi}

Setelah melakukan uji coba alat dengan hasil sesuai dengan rancangan, maka selanjutnya adalah implementasi alat. Kebutuhan aplikasi dan prototype untuk sistem yang akan diimplementasikan adalah sebagai berikut:

1. Kebutuhan aplikasi: 1 aplikasi RTM

2. Kebutuhan Running Text : arduino uno,buzzer,modul dot-matrix 8x8,Bluetooth hc05 ,adapter 12 volt $2 \mathrm{~A}$

3. Kebutuhan Eksekusi: jaringan internet dan jaringan bluetooth

\section{KESIMPULAN}

Dari hasil perancangan alat dan pembahasan pengukur tinggi badan di atas dapat diambil beberapa kesimpulan, di antaranya:

1. Prototipe alat ini menggunakan Smartphone Android dan arduino uno, android di gunakan untuk menerima inputan suara yang nantinya akan di proses oleh arduino, media komunikasi yang di gunakan oleh arduino dan android adalah data serial yang menggunakan Bluetooth HC-05.

2. Pengontrolan running text pada prototype ini menggunakan sebuah applikasi android yaitu Running Text Message untuk merekam sebuah inputan suara, yang akan diproses oleh arduino dengan output yang akan di tampilkan pada running text LED DotMatrix.

3. Menggunakan program Arduino untuk menuliskan listing program dan menyimpannya dengan file yang berekstensi .pde, dan bootloader Arduino Uno sebagai media yang digunakan untuk mengupload program ke dalam mikrokontroller, sehingga mikrokontroller dapat bekerja sesuai dengan yang diperintahkan dengan mengahasilkan running text yang akan ditampilkan.

\section{DAFTAR PUSTAKA}

1. Alpurqon, Agung .2014."Sistem Pengendali Pintu Pagar Otomotasi Menggunakan Aplikasi Voice Command Pada Smartphone Android OS".Skripsi.Tidak di publikasikan.Tangerang : STMIK RAHARJA. Tangerang.

2. Bintar, Muhamad. 2013. Sistem Pengontrolan Lampu Menggunakan Input Suara Berbasis Android. . Skripsi. Tidak diPublikasi. Tangerang. STMIK Raharja.

3. Kuncoro, Sigit Maulana. 2013. SMS Sebagai Perubah Informasi Matriks LED Berbasis AVR ATmega8 Pada Perguruan Tinggi Raharja. Skripsi. Tidak diPublikasi. Tangerang. STMIK Raharja.

4. Nugroho, Evy Christanto Sri. 2010. Papan Informasi Elektronik Dengan PS2 Keyboard. Skripsi. Tidak diPublikasi. Depok: Universitas Indonesia.

5. Purnama, Sandi. 2013 . Perancangan dan Implementasi Sistem Penampilan Running Text dengan Data Berbasis Website. Tugas Akhir. Tidak dipublikasi. Bandung: Universitas Telkom.

6. Pratida, Benny Julisha. 2013. Perancangan Display LED Dot Matrix Menggunakan Mikrokontroler Atmega32. Jurnal Teknik Elketr. Vol 1, No1. STMIK Raharja. Tangerang. 